\title{
Engaging with theory: from theoretically informed to theoretically informative improvement research
}

Alliance Manchester Business School, University of Manchester, Manchester, UK

\section{Correspondence to}

Dr Roman Kislov, Alliance Manchester Business School, University of Manchester, Manchester M13 9SS, UK; roman.kislov@manchester.ac.uk

Accepted 31 October 2018 Published Online First 14 November 2018

\section{Linked}

- http://dx.doi.org/10.1136/ bmjqs-2018-008291

\section{Check for updates}

(C) Author(s) (or their employer(s)) 2019. No commercial re-use. See rights and permissions. Published by BMJ.

To cite: Kislov R.

BMJ Qual Saf

2019;28:177-179.
Repeated calls have been made for the increased use of theory in designing and evaluating improvement and implementation interventions. ${ }^{1-4}$ The benefits are argued to include identifying contextual influences on quality improvement (QI), supporting the generalisability of findings and anticipating how future phenomena might unfold. ${ }^{2}{ }^{5}$ Most importantly, the ability of theories to provide robust explanations is invaluable for understanding how, why and in what circumstances interventions work (or do not work), ${ }^{6}$ thus addressing crucial questions relating, for example, to variation in improvement outcomes. $^{47}$

Although the use of theory in improvement and implementation research appears to be increasing over time, ${ }^{8}$ the emphasis largely remains on adopting a theoretically informed approach, that is, applying theory to design an intervention or to systematise and explain evaluation findings. Despite the recognised need to 'test' theories by scrutinising their assumptions in the light of empirical findings, ${ }^{9}$ improvement researchers are often inclined to treat existing theoretical knowledge as received wisdom which is rarely critiqued and hardly ever moved forward. This often results in a one-way relationship, whereby theory shapes data collection and analysis, but little effort is made to explain what the resulting empirical findings mean for theory.

Part of the problem is that theories may be reduced to lists of 'contextual factors' rather than providing explanations that would uncover causal relationships between them. ${ }^{10}$ This is in contrast to other social science fields, such as organisation and management studies, where theories are seen as 'examined sets of concepts' aiming to reveal previously hidden mechanisms underpinning the development of social phenomena. ${ }^{11}$ Rather than producing exhaustive lists of variables, the aim here is to focus on a relatively limited number of key concepts but explore complex relationships between them in depth. Capturing this complexity in the constantly changing social word requires, however, that theory should be constantly refined. ${ }^{11} 12$

This editorial aims to contribute to this debate by advocating theoretically informative improvement research which, although guided by existing theory, would be able to yield new theoretical insights applicable to a broader range of settings. ${ }^{11}$ This approach implies a dialogue between the theoretical and the empirical, whereby the researcher uses a particular case or set of cases as an opportunity for further refining previous conceptualisations of the general processes contained in the earlier theoretical accounts. ${ }^{12}$ I will use the Jones $e t a l^{13}$ paper in this issue as an example of successfully deployed theoretically informative approach, highlighting some practical tips for researchers who aspire to move from merely applying theory towards entering into dialogue with it and, through doing so, refining its assumptions.

First, it is important to find a balance between the empirical question 'What is going on here?' and the theoretical question "What is this a case of?"12 Jones et al ${ }^{13}$ make it clear at the outset that they aim to understand 'the response of healthcare provider organisations to a board-level QI intervention', which involved the use of a researchbased guide for senior hospital leaders to 
develop and implement organisation-wide QI strategies. ${ }^{14}$ This sets their study in a novel empirical context. However, they do not stop here, but position their study theoretically as a case of 'corruption of managerial techniques', a notion first introduced by Lozeau et al. ${ }^{15}$ Jones and colleagues ${ }^{13}$ make a theoretical claim that the diversity of QI outcomes can be explained by different ways of closing the 'compatibility gap' between the assumptions underpinning the proposed board-level intervention (eg, an assumption that there is a functional board) and the characteristics of the adopting organisation (eg, the actual configuration of the board). An examination of this claim sets in motion a fruitful dialogue between the theoretical and the empirical.

The next step involves positioning the empirical case under investigation against earlier studies that have contributed to the formulation and development of the relevant theory. Since theorising is an iterative and recursive process, ${ }^{12} 16$ it is important to consider previous empirical studies building on the relevant theory rather than solely rely on the original theoretical account. ${ }^{16}$ Whether the theoretical approach is chosen prospectively (prior to data collection) or retrospectively (at the data analysis stage, as is the case in the Jones et $a l^{13}$ paper), this enables the researcher to paint the stateof-the art picture of what is already known, identify gaps in theoretical knowledge and, subsequently, focus on addressing them. Not only do Jones et $\mathrm{al}^{13}$ draw on the original Lozeau et $a l^{15}$ paper, they also find valuable insights in subsequent studies exploring the distortion of managerial techniques in organisations. For instance, they engage with such ideas as the possibility of top-down distortion described by Addicott $e t ~ a l^{17}$ in their study of healthcare networks and the erosion of staff engagement over time highlighted by Kislov et a ${ }^{18}$ in their longitudinal study of facilitation in a collaborative research partnership. ${ }^{18}$

Third, when analysing empirical data in a theoretically informative way, it is crucial to move beyond simply cataloguing different contextual factors towards exploring how these factors work together, mediating QI outcomes. ${ }^{3} 7$ This often involves mining and reducing the data in a search for more general patterns. ${ }^{19}$ As a result, broader categories or themes are identified, bringing together multiple contextual factors and highlighting generative mechanisms through which improvement interventions lead (or do not lead) to intended outcomes. For instance, Jones and colleagues' ${ }^{13}$ use of the notion of 'organisational slack' reflects the complex inter-relationship between contextual factors both external to the organisation (eg, its regulatory environment) and internal to it (eg, the organisation's own performance or its approaches to constructing the portfolios of improvement projects). Exploring connections between these factors across different cases advances our understanding of mechanisms underpinning the implementation of organisational QI interventions.
Finally, analysis and interpretation of findings should not be limited to finding similarities between the empirical case and extant theory, but aim to identify and explicate the differences, thus moving theory forward. ${ }^{12}$ The key task here is to explain what these differences mean for our understanding of theory and in what way, no matter how minor, this understanding is expanded, clarified or amended by the empirical case under investigation. Jones and colleagues ${ }^{13}$ accomplish this by identifying a new mechanism underpinning the phenomenon of 'loose coupling', which is usually seen as superficial or ritualistic participation in the intervention. They interpret loose coupling as inaction or 'stalling' induced by external regulatory environment, whereby hospitals become overburdened by multiple improvement initiatives operating at the same time and therefore have to prioritise their improvement efforts. Another theoretical contribution of their paper lies in highlighting the importance of collective change agency (here in the form of a well-functioning board, in which stable, coherent and collegiate leadership leads to 'mature' QI governance) in closing the 'compatibility gap'. This is an important finding that does not feature as prominently in the original formulation of the theory.

The approach taken by Jones and colleagues ${ }^{13}$ represents one of the multiple ways of entering into dialogue with theory. Prospective use of theory to identify relevant research gaps and to guide data collection offers a potentially valuable alternative to post-hoc theorising deployed at the data analysis stage. It is also important to remember that every theory is inherently selective and one-sided, guiding its users towards certain aspects of the phenomenon at the expense of others. ${ }^{11}$ Jones et al's ${ }^{13}$ conclusions might well have been quite different had they engaged with another theory, for instance absorptive capacity, ${ }^{7}$ to analyse their findings. Finally, since the process of theorising is always incomplete, ${ }^{12}$ in many cases it may be perfectly legitimate to adopt an even more critical stance towards existing theories, whereby the empirical researcher draws 'ever finer distinctions, ${ }^{20}$ and thus helps build a cumulative understanding of the general processes and mechanisms of change.

\section{Twitter@RomanKislov}

Acknowledgements This work was supported by the National Institute for Health Research Collaboration for Leadership in Applied Health Research and Care (NIHR CLAHRC) Greater Manchester. The views expressed in this article are those of the author and not necessarily those of the NHS, NIHR or the Department of Health and Social Care. I am also grateful to Paul Wilson for fruitful discussions, which were invaluable for refining ideas presented in this article, and to Mary DixonWoods for helpful editorial guidance.

Funding The authors have not declared a specific grant for this research from any funding agency in the public, commercial or not-for-profit sectors.

Competing interests None declared.

Patient consent Not required. 
Provenance and peer review Commissioned; internally peer reviewed.

\section{REFERENCES}

1 Davidoff F, Dixon-Woods M, Leviton L, et al. Demystifying theory and its use in improvement. BMJ Qual Saf $2015 ; 24: 228-38$.

2 Foy R, Ovretveit J, Shekelle PG, et al. The role of theory in research to develop and evaluate the implementation of patient safety practices. BMJ Qual Saf 2011;20:453-9.

3 Davies P, Walker AE, Grimshaw JM. A systematic review of the use of theory in the design of guideline dissemination and implementation strategies and interpretation of the results of rigorous evaluations. Implement Sci 2010;5:14.

4 Colquhoun HL, Brehaut JC, Sales A, et al. A systematic review of the use of theory in randomized controlled trials of audit and feedback. Implement Sci 2013;8:66.

5 May CR, Mair F, Finch T, et al. Development of a theory of implementation and integration: normalization process theory. Implement Sci 2009;4:29.

6 Kislov R, Wilson PM, Knowles S, et al. Learning from the emergence of NIHR Collaborations for Leadership in Applied Health Research and Care (CLAHRCs): a systematic review of evaluations. Implement Sci 2018;13:111.

7 Harvey G, Jas P, Walshe K. Analysing organisational context: case studies on the contribution of absorptive capacity theory to understanding inter-organisational variation in performance improvement. BMJ Qual Saf 2015;24:48-55.

8 Liang L, Bernhardsson S, Vernooij RWM, et al. Use of theory to plan or evaluate guideline implementation among physicians: a scoping review. Implementation Science 2017;12.

9 Gardner B, Whittington C, McAteer J, et al. Using theory to synthesise evidence from behaviour change interventions: the example of audit and feedback. Soc Sci Med 2010;70:1618-25.

10 Birken SA, Bunger AC, Powell BJ, et al. Organizational theory for dissemination and implementation research. Implement Sci 2017;12:62.
11 Sayer A. Method in social science: a realist approach. 2nd edn. Oxon: Routledge, 2010.

12 Tsoukas H. Craving for generality and small-N studies: a Wittgensteinian approach towards the epistemology of the particular in organization and management studies. In: Buchanan D, Bryman A, eds. SAGE handbook of organizational research methods. London: SAGE Publications, 2009: 285-301.

13 Jones L, Pomeroy L, Robert G, et al. Explaining organisational responses to a board-level quality improvement intervention: findings from an evaluation in six providers in the English National Health Service. BMJ Qual Saf 2019;28:198-204.

14 QUASER. The Hospital Guide. 2014. Available: https://www. ucl.ac.uk/dahr/pdf/study_documents/iQUASER_Hospital_ Guide_291014_press-ready_cs4.pdf

15 Lozeau D, Langley A, Denis J-L. The corruption of managerial techniques by organizations. Human Relations 2002;55:537-64.

16 May CR, Cummings A, Girling M, et al. Using normalization process theory in feasibility studies and process evaluations of complex healthcare interventions: a systematic review. Implement Sci 2018;13:80.

17 Addicott R, McGivern G, Ferlie E. The distortion of a managerial technique? The case of clinical networks in UK health care. British Journal of Management 2007;18:93-105.

18 Kislov R, Humphreys J, Harvey G. How do managerial techniques evolve over time? The distortion of "facilitation" in healthcare service improvement. Public Management Review 2017;19:1165-83.

19 Cornelissen JP. preserving theoretical divergence in management research: why the explanatory potential of qualitative research should be harnessed rather than suppressed. Journal of Management Studies 2017;54:368-83.

20 Tsoukas H. Don't simplify, complexify: from disjunctive to conjunctive theorizing in organization and management studies. Journal of Management Studies 2017;54:132-53. 